\title{
ON KEEPING THINGS IN PROPORTION
}

\author{
Adam Lovett and Stefan Riedener
}

OANNA IS THE VICTIM of a natural disaster. A drought has caused the har-
vest to fail. She does not have enough food. You donate one hundred dollars
to the Red Cross and that gets her the food she desperately needs. This is a good thing, and for a while it seems you have done something very important. You have saved a life! But then you get some perspective. You realize that Joanna is not the only victim of this natural disaster. The drought has struck her entire community, even her entire nation. Millions of people are at risk of starvation. You have saved a tiny proportion of them. Now the significance of your action seems diminished. It seems to matter somewhat less. We will call this the Drop in the Ocean Intuition. The intuition is that the fact that your action makes a tiny dent in the overall extent of suffering diminishes its importance. Your contribution matters less when it is a drop in the ocean.

Some philosophers think this intuition is hopeless. Jonathan Glover calls it a "context illusion." He claims that "it can be dismissed at once." Peter Unger calls it "futility thinking." He says that "when [gripped by this intuition] you're greatly influenced by a consideration which is morally irrelevant." 2 Peter Singer holds that the intuition "doesn't stand up to examination." ${ }^{3}$ William MacAskill says it "doesn't make any sense." a view that validates some form of this intuition. We think that only when we have such a view on the table can we assess its plausibility.

The view we want to explore is simple. It says that a thing's importance depends on how big a proportional contribution it makes to the world's total value. For example, consider the addition of one happy life. According to this view, the importance of this addition depends on what is going on elsewhere in the

1 Glover and Scott-Taggart, "It Makes No Difference Whether or Not I Do It," 172.

2 Unger, Living High and Letting Die, 63.

3 Singer, The Life You Can Save, 59. In the passage this comes from Singer is referring to the intuition that we should favor saving people we see over people we do not see. But he then says "the same is true" for the Drop in the Ocean Intuition.

4 MacAskill, Doing Good Better, 30. 
universe. If the universe contains just one happy life, then the addition involves a great proportional improvement. So it is very important. But if instead the universe contains a hundred billion happy lives, then the addition is a tiny proportional improvement. So it is not very important. The number of happy lives in the universe affects the importance of the addition of one more happy life. We will call this view Proportionalism. ${ }^{5}$

Proportionalism implies that the relative insignificance of saving Joanna does indeed diminish its importance. But it does not validate everything involved with the Drop in the Ocean Intuition. Some people, for instance, think that if saving Joanna is just a drop in the ocean, then we may as well indulge ourselves instead. Go buy yourself priority boarding! But this need not follow. Your reason to save Joanna may be diminished by its proportional insignificance. But so is your reason to indulge yourself. And they are diminished in proportion to their original weight. So, the relative dominance of the former is untouched. Other people misapply proportional thinking. They take the importance of something to be the proportional contribution it makes to a specific issue. For instance, suppose two populations are suffering famine. Some people prefer saving 75 percent of the smaller population to saving 25 percent of the much larger one, even if this saves fewer lives overall. ${ }^{6}$ According to Proportionalism, these people are making a mistake. It is not the size of the specific problem that matters. It is the size of the whole world. These people are using the wrong reference class. Proportionalism, then, is not meant to validate everything involved with the Drop in the Ocean Intuition. It is only meant to validate its core.

In the rest of the paper we explore this view. In section 2, we formulate Proportionalism precisely. In sections $3-5$, we look at its further motivation. In section 6, we see how to extend it. In these later sections we also show how versatile Proportionalism is. We will see an agent-relative version of the view (section 5.1). We will see versions of it restricted to certain kinds of facts (section 5.4)

5 Nick Bostrom talks about this view in his "Infinite Ethics." He says: "We might constitute a minute portion of the whole, but that does not detract from our absolute importance" ("Infinite Ethics," 10). In other words, he dismisses Proportionalism out of hand. We have come across no other prior discussion of Proportionalism.

6 Psychologists call this phenomenon "proportion dominance" (Bartels, "Proportion Dominance"), "psychological numbing" (Fetherstonhaugh et al., "Insensitivity to the Value of Human Life"), or the "reference group effect" (Loewenstein and Jenni, "Explaining the 'Identifiable Victim Effect'”). They have studied the phenomenon extensively. In one study, Daniel Bartels asked subjects to choose between either a program that saved 225 lives of 230 at risk, or one that saved 230 lives of 920 at risk ("Proportion Dominance"). Almost half chose the former. They took the greater proportion of the at-risk population saved to be of greater moral weight than the extra lives. We think it is a strength of Proportionalism that it can help explain why people make this mistake. 
and types of normativity (section 5.6). And we will see how it fits into a much broader phenomenon: proportional thinking (section 6.1). But let us not get ahead of ourselves. We will first locate the notion of importance that matters to Proportionalism.

\section{CHARACTERIZING IMPORTANCE}

The Drop in the Ocean Intuition involves importance or significance. So we need to give an account of how important or significant something is. Our notion of importance is not the axiological notion. For something to be important, in our sense, is not for it to be worth promoting. Our notion is instead understood in terms of fitting attitudes. How important something is is how much it is fitting to care about it. What is it for an attitude to be fitting? For us, it is just for it to be permissible to have that attitude. So, we characterize our notion of importance with the following principle:

Caring: How important something is just is the most one is permitted to care about it.

The relevant type of permissibility is that which rules attitudes of caring. This is not the same as moral, prudential, or epistemic permissibility. It is a distinctive normativity that governs how much we care about things. We think there is such a type of normativity because, intuitively, one's attitudes of caring can be mistaken in distinctive ways. We all know people who care more than anything about long-gone sporting victories. Their attitudes are out of whack; they are making a mistake. But this need not be a moral or prudential mistake. Still less must it be an epistemic mistake. Rather, it is a mistake parochial to attitudes of caring. So, there seems to be a distinctive normativity that governs such attitudes. ${ }^{7}$ Of course, there may still be interesting connections between this type of normativity and other types of normativity. For example, we are inclined to think that one has moral reason to care fittingly about things that matter morally. If you care about football more than famines, then your attitudes are not just unfitting: they are morally defective. But there remains a distinction between moral permissibility and that which governs attitudes of caring. It is this second type of normativity that matters for our notion of importance.

7 We admit that there are hard questions about how to demarcate the reasons relevant to this kind of normativity. But these questions do not relate to the phenomenon we are concerned with. So we will put them aside for the rest of the paper. For these questions see, e.g., D’Arms and Jacobson, "The Moralistic Fallacy”; Rabinowicz and Rønnow-Rasmussen, "The Strike of the Demon"; Bykvist, "No Good Fit." 
What is it to care about something? For us, "caring" refers to any emotional response. Adoration and adulation are types of caring. But so too are abhorrence and apprehension: you can care about something by hating it just as much as by loving it. Such attitudes have a phenomenological character. There is a certain way it feels to care about something. It seems plausible that they also have an evaluative character. Perhaps caring about something involves valuing (or disvaluing) it. And maybe caring is constitutively connected to actions. Perhaps adoring something involves being disposed to promote or preserve it. Perhaps despising something involves being disposed to prevent or destroy it. We take no stand on this final issue. We are neutral about whether there are such connections between caring and behavior. The account of importance we give would be tenable were there such connections. But it would still be interesting without them. The key thing is that, when we talk about caring about something, we are talking about whatever is involved in emotionally responding to that thing.

Caring defines importance in terms of how much one can care about something. So what is it to care some amount about something? Here we have a choice. The first option conceives of caring as an absolute quantity. How much one cares about something is how intensely and for how long one cares about it. The second option conceives of caring as a share. How much one cares about something is what share of one's emotional life one devotes to it. The two come apart when people have different emotional capacities. Consider a person who is incapable of caring a large quantity about anything. They might nonetheless devote their entire emotional life to their family. Then they will not care much about their family in the first sense, but will in the second. We are neutral between these options. We think Proportionalism is tenable on either option.

Caring also does not settle who is doing the relevant caring. Here we have a second choice. One option is to relativize importance to each individual. On this interpretation, how important something is for Adam is how much it is permissible for Adam to care about that thing. We have a multitude of importance rankings, one for each person. But one can also (or instead) define a non-relativized notion of importance. There are a couple of ways to do this. First, one might define such a notion out of the relativized notions. This is easiest if we assume everyone's importance ranking is the same. That is, everyone is permitted to care to the same degree about everything. Then one can say that how important something is (simpliciter) is how much it is permissible for anyone to care about that thing. Second, one could invoke the emotional life of some ideal observer. So how important something is is how much it is permissible for a fully 
informed, imaginative, and impartial observer to care about it. ${ }^{8}$ Again, we think Proportionalism is tenable on any of these options. For now, what matters is that we cash out our notion of importance in terms of maximum permissible degrees of caring. How important something is is the maximum emotional response it is fitting or permissible to have toward that thing.

This is not the only notion of importance. We have mentioned the axiological notion already. But, more saliently, there is also a notion of importance involving minimum permissible degrees of caring. On this notion, how important something is is the minimum one ought to care about it. We think the maximum-permissible notion is more interesting. This is because we doubt there is often a minimum degree to which one ought to care about things. We will explain why in section 5.3. But, for now, let us just note that very little we say depends on this. Almost everything we say could be changed to fit the minimum-permissible notion. ${ }^{9}$ So, we go forward with the maximum-permissible notion. This paper is about the most one is permitted to care about things.

\section{PROPORTIONALISM}

We now express Proportionalism a bit more precisely. Let us first characterize a notion of normative mass. To do this we assume that some kinds of intrinsic properties invite an emotional response. These are the properties that intrinsically matter. How much normative mass something has is how much of these properties it contains. For example, one might think that joy and suffering were all that intrinsically mattered. That is, one might think that these are the only kinds of intrinsic properties you can permissibly care about. Then the normative mass of something is just how much joy it contains and how much suffering it contains. Compare a long marriage to a short fling. The former might contain a lot of joy and a lot of suffering. So it might have relatively great normative mass. The fling hopefully contains some joy but perhaps also some suffering. Yet probably much less of both. So it has relatively little normative mass. Of course, joy and suffering are likely not the only things that matter intrinsically. Maybe beauty matters. Maybe fearsomeness matters. Maybe it matters that you violated someone's rights. Then these too will contribute to normative mass. But joy and suffering are likely contributors to normative mass.

What kind of things have normative mass? Not much swings on this. But we will treat facts as the bearers of normative mass. We think of facts as proper-

8 There is a venerable tradition that invokes such observers in ethics. See, e.g., Firth, "Ethical Absolutism and the Ideal Observer"; Railton, "Moral Realism”; Smith, The Moral Problem.

9 We note the only substantial change in note 16 , below. 
ty instantiations and conjunctions thereof. Your marriage, for example, can be thought of as the conjunction of some of the facts involving you and your partner. We will say the normative mass of a fact is how weighty are the properties that make it up. A weighty marriage may be one that is constituted by much joy and suffering. One important bearer of normative mass is the entire universe. We will treat this as the conjunction of all the property instantiations. The normative mass of the entire universe is how much of what matters there is anywhere. So, if there is a lot of joy and suffering, we have a heavyweight universe. If there is not much of either, our universe may be lightweight. The key thing is that the normative mass of a fact is how much of the properties that intrinsically matter it contains.

We can now state our view. Let $I(f)$ be how important $f$ is. Let $N M(f)$ be $f$ 's normative mass. Let $N M(U)$ be the normative mass of the entire universe. Then Proportionalism says:

$$
I(f)=\frac{N M(f)}{N M(U)} .
$$

In other words, how important $f$ is is determined by $f$ 's share of the normative mass of the whole universe. Remember you can interpret $I(f)$ either as an absolute quantity of caring or as a share of your emotional life. ${ }^{10}$ So this says how much you can care about something depends on the proportion of the universe's total normative mass it makes up. For example, the fling probably makes up a smaller proportion of the universe's total normative mass than the marriage. So you can care about it less. Your headache probably makes up a lesser proportion than both of these things. So you can care about it still less. And getting priority boarding? You can care hardly at all about that.

This view captures the Drop in the Ocean Intuition. This is because the weightier the universe is, the less important is an event of given normative mass. So, seeing how much joy and suffering there is in the world should make one's own contribution seem of diminished importance. In particular, seeing that Joanna's suffering is just a drop in a whole ocean of sorrow makes alleviating it less important. This alleviation is still good. But it makes up a smaller share of the total joy and suffering in the world. This is the initial motivation for the view. We now explore Proportionalism a bit further. In particular, we will bring out some

On the first interpretation, you need some way of mapping numbers to absolute quantities of caring. To do this, start by saying that o maps to no caring at all. Then pick some $n$ to map to some given amount of caring. Perhaps, for instance, 0.001 maps to a mild tinge of homesickness. Then, for any $k, I(f)=k$ just in case the amount of caring you can devote to $f$ is $k / 0.001$ times that of the homesickness. 
interesting features of the view by comparing it to two alternative accounts of importance.

\subsection{Intrinsicism}

Let us first see how our view relates to the most natural alternative. This alternative says that the importance of a fact just is how much of what intrinsically matters inheres in the fact. In other words:

$$
I(f)=N M(f) .
$$

Call this alternative Intrinsicism. Within a given universe, the importance ranking of our view and that of Intrinsicism perfectly coincide. If any two facts, $f$ and $g$, occur in some universe, then Intrinsicism says $f$ is at least as important as $g$ if and only if our view says $f$ is at least as important as $g$. We think this is a nice feature of our view.

But Intrinsicism and Proportionalism are otherwise quite different. According to Intrinsicism, all that matters to how important something is is its intrinsic properties. Proportionalism says that how it relates to something else-the entire universe-also matters. The most severe consequences of this are modal. Intrinsicism implies that intrinsic duplicates keep the same importance across possible worlds. Consider a world in which nothing much happens but a headache. Suppose you are permitted to care to some degree about the headache in this world. Now consider a world in which a duplicate of the headache happens. But suppose many other things that matter also happen. Intrinsicism implies that you are permitted to care to exactly the same degree about the headache in this other world. But Proportionalism implies the opposite. Proportionalism implies that you cannot care as much about the headache in the second world. This is because it makes up a lesser proportion of that world's normative mass. So these views differ on the importance of intrinsic duplicates.

This difference might seem detrimental to Proportionalism. Compare the lonely headache to a murder in a world full of joys and suffering. The headache makes up a large proportional share of the normative mass of its universe. The murder does not. So, on Proportionalism, the former is more important than the latter. But, one might think, surely a murder must be more important than a headache? If so, Proportionalism gets these cases wrong. But we think not. Now we do think there is something right about this thought. When a murder and a headache happen in the same world, you should care about the murder more. But the thought is not just that. It is that, even if a headache were all that ever happened, you should care less about it than you should about a murder in a well-populated world. To us, this does not seem intuitively obvious. Indeed, 
there is reason to doubt it. It is in tension with the Drop in the Ocean Intuition. The murder is just a drop in the ocean. The headache is the ocean. So if drops are less important the less of an ocean they make up, the murder must be less important than the headache. So, we doubt this difference is detrimental to Proportionalism. But there is more to be said, so we return to Intrinsicism in section 5 .

\subsection{Averagism}

Now let us see how our view relates to another alternative. This alternative says that how important a fact is is how much more (or less) normative mass that fact has than the average fact. In other words:

$$
I(f)=|N M(\bar{f})-N M(f)|,
$$

where $(\bar{f})$ is the mean normative mass. Call this alternative Averagism. Both our view and Averagism say that the importance of a fact depends on the importance of other facts. But Averagism says that such issues can change the relative importance of two facts. Proportionalism never goes that far. According to Proportionalism, such issues only ever change the absolute importance of a fact.

How does this make a difference? Consider the ancient Egyptians. ${ }^{11}$ Suppose facts about the past have normative mass. Now imagine that the ancient Egyptians had a far more flourishing society than we currently believe. Suppose they lived glorious lives and there were a lot of them to boot. According to Averagism, this would make currently splendid lives less important. They would be closer to the average. But it would make currently mediocre lives much more important. They would be further below the average. So, on Averagism, facts about ancient Egypt can affect which things are more important than which other things. But that is not so on Proportionalism. According to Proportionalism, the Egyptians' fate cannot affect the relative importance of things. It can make some things of less absolute importance than they would otherwise be. But it cannot affect which things are more important than which other things. We think the consequence of Averagism here is implausible. But that of Proportionalism is tenable. But again there is more to be said. So we will return to the issue in section 4 .

\subsection{Empty Worlds}

A final interesting way these views relate lies in how they treat empty worlds. These are worlds that contain nothing that matters: everything in them has zero normative mass. According to both Intrinsicism and Averagism, everything in

11 Jeff McMahan first discovered that ancient Egyptology mattered for some moral theoriesspecifically, average utilitarianism ("Problems of Population Theory," 115). But Derek Parfit made the point prominent (Reasons and Persons, 420). 
an empty world has zero importance. Intrinsicism says this because it says the importance of a thing is just its normative mass, which is zero. Averagism says this because it says that the importance of a thing is the difference between its normative mass and the average normative mass. In an empty world the average normative mass is zero and everything has exactly this normative mass. So both views attribute everything in an empty world zero importance. But according to Proportionalism, the importance of anything in an empty world is undefined. That is because the normative mass of an empty world is zero. And you cannot divide by zero. So you cannot assess the importance of anything in an empty world.

We think this is a feature of Proportionalism, not a bug. To see why, consider what must be the case in an empty world. By definition, no facts have any normative mass in such a world. But now consider facts about the permissibility of attitudes. Suppose such facts had normative mass. Then they could not be in an empty world. But we think such permissibility facts do have normative mass. We think this because it matters whether there is a maximum amount you can care about something. This matters even—or especially—if this maximum amount is o. This is because you can care that o is the most you can care about something. ${ }^{12}$ So no such permissibility facts must obtain in the empty world. But this just amounts to the claim that the importance of everything in such a world is undefined. So, our view gets the right results in this case.

But this might be denied. Perhaps we are wrong to think that facts about what is important themselves have normative mass. Even so, we do not think this would be a significant problem. This is because we doubt it is metaphysically possible for a universe to be normatively empty. We doubt this because we think various modal facts have normative mass. Consider the fact that there could have been intelligent life. We think that this fact matters. Indeed, if there is no intelligent life this fact is grounds for regret. But plausibly every possible universe must contain facts like this. So every possible universe has at least some normative mass. So, how Proportionalism treats empty worlds is a feature, not a bug. ${ }^{13}$

Does it matter that you cannot care more than some amount about the fact that you cannot care more than some amount about some fact? And so on? We think so. But such facts about permissibility plausibly matter less and less the higher up you go, so do not matter infinitely much in total. For instance, the normative mass of these permissibility facts may be characterized by the sequence $1 / 2,1 / 4,1 / 8, \ldots$, such that their total normative mass is 1 (since $\left.\sum_{n=1}^{\infty}(1 / 2)^{n}=1\right)$. So we do not think that this kind of regress presents a problem.

13 But perhaps this is wrong. Nonetheless, Proportionalism could easily be modified. We could treat facts in non-empty worlds as dictated by Proportionalism, but stipulate that the importance of everything in an empty world is o. This is a little inelegant. But a little inelegance ain't fatal. 


\section{THE INSIGNIFICANT SPECK INTUITION}

We now turn to providing further motivation for the view. So far, we have just claimed it captures a widespread intuition: the Drop in the Ocean Intuition. But we think it can also capture another common intuition:

The Insignificant Speck Intuition: Look up at the stars. There are a lot of them. In fact, there are $10^{13}$ of them in our supercluster alone. That is one followed by thirteen zeros. And our supercluster is just one in ten million superclusters. That is a lot of stars. The universe is vast and awe-inspiring. You, your actions, everyone you know, the whole history of your civilization and species is just a tiny speck in this vast universe. This realization can make all these things seem less important. The fact that the universe is vast beyond comprehension reduces the significance of your own actions.

Here is how Proportionalism can capture this. Above, we suggested that the normative mass of a world might be the amount of joy and suffering it contains. But this is quite a limited view. We already mentioned that beauty or fearsomeness might contribute to the normative mass of the world. And the list need not stop there: in particular, we think that awesomeness, in the sense of worthiness of awe, may contribute to normative mass. And it is plausible that the sheer size of our universe is awesome. So, given our account of importance, the vastness of the universe should diminish the importance of our actions. This is the Insignificant Speck Intuition.

This is not to say that these are the only considerations at play in the Insignificant Speck Intuition. Like with the Drop in the Ocean Intuition, other things may also play a role. Nagel, for instance, claims that the Insignificant Speck Intuition conveys the absurdity of our lives. He takes this to amount to "the collision between the seriousness with which we take our own lives and the perpetual possibility of regarding everything about which we are serious as arbitrary."14 Perhaps. And if so, our view will not capture this aspect of the intuition. But we think this is not all there is to the intuition. We are not merely aware of the arbitrariness of our aspirations; we are aware of the insignificance of our concerns when measured against the vastness of the universe. Our view can capture this aspect of the Insignificant Speck Intuition. 


\section{A DEEPER MOTIVATION}

The evidence we have just given for our view is intuitive fit. It captures various intuitions we think are widespread. This type of motivation is not to be sneezed at. Many good philosophical theories are justified by intuitive fit alone. But we can also give Proportionalism a deeper motivation. This motivation is not essential: you can accept the view without accepting this motivation. But we ourselves think this motivation provides strong support for Proportionalism. It shows that the view follows from some assumptions that we find compelling.

Roughly, the deeper motivation goes like this: to have fitting attitudes, your attitudes have to be proportional to how much things matter. A person suffering in front of you matters much more than the fact that your paper got rejected. So it would be unfitting to care more about the paper than the person. But you are a finite being with finite conative resources. There is only so much you can care about things. So consider what happens when you move through universes where more and more things matter. Because of your conative limits you cannot keep expanding how much you care about things willy-nilly. So, to keep your attitudes in proportion, you need to reduce how much you care about your paper's rejection. So how much you can care about the rejection is proportional to the normative mass of the universe. In universes where more matters, you have to care about it less. But this, if you squint right, is Proportionalism.

That is a rough statement. Now let us go a bit more carefully. We first define what it is to have overall fitting degrees of caring. This means that every collection of your degrees of caring is permissible. We now state our first assumption. This is the assumption that your degrees of caring are overall fitting if and only if they are proportional to the normative mass of facts. This assumption is made up of a necessary and a sufficient condition. The necessary condition says that it is necessary for overall fittingness that your attitudes are in proportion to the normative mass of things. So if you care much more about the paper than the person, your degrees of caring cannot be fitting. The sufficient condition says that this is also sufficient for overall fittingness. So if you care proportionally about the paper and the person (and everything else), then your degrees of caring are fitting. We can put this as follows:

Congruity: Necessarily, your overall degrees of caring are fitting if and only if, for any facts $f$ and $g$, if the normative mass of $f$ is $n$ times greater than the normative mass of $g$, you care $n$ times more about $f$ than about $g$.

We expect Congruity to be controversial. We will discuss objections to it in sections 5.1-5.4. But we think it has strong prima facie plausibility. And we think 
we can answer the objections. So we think it grounds a credible motivation for proportional thinking.

We also rely on a second assumption. This assumption is twofold. First, we assume that there is a maximum degree you are able to care about things. The idea here is just that you are a finite being with finite emotional resources. If you were a god perhaps you could care without bound. But you are not a god: there is a limit to the intensity and duration you can care about things. Second, we assume that you can have any collection of caring attitudes that together do not exceed this limit. In the relevant sense of "can," the only constraint on your caring attitudes is that you have limited conative resources. To put this another way:

Limits: There is a maximum amount, $T$, you are able to care about things,

but any collection of attitudes consistent with this limit is possible.

In what follows, we will stipulate that $T=1$. This is required to get the precise formulation of our view. But nothing deep swings on this: it is just an arbitrary choice about which number represents the limit. This aside, when it comes to Limits we think the claim that we are not gods will be uncontroversial. But the claim that you could have any attitudes that do not exceed the limit might be controversial. We will discuss this in section 5.5.

These are our two primary assumptions. These assumptions alone have a very interesting consequence. They entail that for any fact, $f$, the maximal degree you are able to care about $f$ consistent with you having overall fitting attitudes is:

$$
\frac{N M(f)}{N M(U)}
$$

This just is our formula for $I(f)$. Thus the maximal degree you can care about $f$ while having overall fitting attitudes is the proportion of the universe's total normative mass that $f$ represents. This means that these assumptions alone get us very close to Proportionalism.

We will just give an informal proof that this entailment holds. ${ }^{15}$ Consider any fact, $f$. If the share of your maximal total degree of caring that you devote to $f$ is

15 Whenever we give an informal proof, we have a formal proof that we do not include. In this footnote we will outline the relevant formalization of these assumptions. But we will not provide the whole proof. We begin by setting up a framework. Remember we defined a fact as a property-instantiation or a conjunction thereof. We will represent a conjunction of property-instantiations as a set. So let $\Omega=\left\{f_{1}, f_{2}, \ldots, f_{n}\right\}$ be the set of property-instantiations. This means $\Omega$ represents the entire universe. Let $\wp(\Omega)$ be the set of all subsets of $\Omega$ (i.e., its power set). So this represents the set of all facts. Let $N M$ be a non-negative function of facts representing the normative mass of a fact. Let $c$ be a non-negative function of facts representing how much you care about a fact. Finally, let fit represent the fact that you have 
greater than $f$ s share of the normative mass of the universe, then you cannot care proportionally about every other fact. This is because if you cared proportionally about every other fact, your total degrees of caring would exceed 1. So your overall attitudes cannot be fitting. If the share of your maximal total degree of caring that you devote to $f$ is precisely equal to $f$ 's share of the normative mass of the universe, then you can care proportionally about every other fact: you will do so if the share of your maximal total degree of caring that you devote to any other fact $g$ is precisely equal to $g$ 's share of the normative mass of the universe. So your overall attitudes can then be fitting. So this formula describes the maximum degree you can care about $f$ consistent with having overall fitting attitudes.

This is an interesting result. But it does not quite yet give us our account of importance. This is because we said how important something is is the most you can fittingly care about it. We just showed that caring too much about something entails your overall attitudes cannot be fitting. But this does not mean that this very attitude is unfitting. Having it might ensure some other attitude (or collection thereof) is unfitting, but it need not be unfitting itself. So, to get our account, we need the following:

Necessary Means: If $p$ necessarily implies that you violate some of your obligations, then you ought to see to it that $\neg p$.

This is a necessary means principle. It says you ought to see to the necessary means to not violating your obligations. We think such a principle explains why you should not make promises you cannot keep or have children you cannot care for. Doing so ensures you will violate an obligation. So we find this principle very plausible. Yet it is not beyond dispute. We discuss an objection to it in section 5.6. But for now, let us see how this leads to Proportionalism.

Here is an informal proof. Recall that $I(f)$ denotes the normative mass of

overall fitting degrees of caring. In this framework, we can formalize our two principles as follows:

Congruity (formal): fit $\leftrightarrow$ for all $F$ and $G$ in $\wp(\Omega)$ and any real number $t$ such that $N M(F)=t \times N M(G), c(F)=t \times c(G)$.

Limits (formal): $c(\Omega) \leq 1$.

Two notes about this formalization. First, we should interpret these principles as necessarily true. Second, Limits (formal) just captures the first conjunct of Limits. The second conjunct is captured by the fact that this is the only constraint we assume on $c$. Assuming that $N M(\Omega)>0$ it can be shown that for any $F$ in $\wp(\Omega), N M(F) / N M(\Omega)$ is the maximal value $c(F)$ can take while Congruity and Limits hold and fit is true. That is, in light of these assumptions, $F$ 's share of the universe's total normative mass represents the maximum you can care about $F$ while having overall fitting degrees of caring. 
$f$ over that of the entire universe. Suppose this is the maximum one can care about $f$ consistent with having overall fitting degrees of caring. So, if you care more than $I(f)$ about $f$, you must lack overall fitting degrees of caring. But that you lack overall fitting degrees of caring just means that some collection of your attitudes is impermissible. So, you violate one of your obligations. So by Necessary Means, you ought not care any more than $I(f)$ about $f$. Next, recall that it is possible for you to care exactly to degree $I(f)$ about $f$ while still having overall fitting degrees of caring. But this_caring to degree $I(f)$ about $f$-is itself a degree of caring. So, if you can have this attitude and have overall fitting degrees of caring, this attitude can itself be permissible. So it is possible for your caring exactly to degree $I(f)$ about $f$ to be permissible. So $I(f)$ is the maximum you can permissibly care about $f$.

This completes the deeper motivation for our view. ${ }^{16}$ Roughly, Proportionalism follows from the need to keep our attitudes in proportion while being constrained by our human limitations. With this in hand, we can see better where Proportionalism and its competitors come apart. ${ }^{17}$ If you deny Proportionalism, you must reject Limits, Congruity, or Necessary Means. Let us make this vivid

This is where the distinction between the maximum-permissible and the minimum-permissible notions of importance (from section 1) makes a difference. We could have characterized importance as a measure of the minimum one ought to care about something. For this notion of importance, our exact argument does not go through. This is because the right-left of Congruity implies there are no such minimums. But a closely related argument does. The related argument endorses the left-right of Congruity and endorses Lower Limits. Lower Limits says you must use some positive minimum proportion of your emotional resources. You must use, let us say, at least one percent of your emotional resources. Now consider any fact, $f$. Identify the fraction of the universe's total normative mass $f$ makes up. Suppose you devoted less than 1 percent of this fraction of your emotional life to $f$. Then you could not care about all other facts proportionally. For suppose you did. Then you would not end up using even 1 percent of your emotional resources. In other words, in order to have proportionate attitudes that exceed the lower limit, the minimum degree you care about anything must be proportionate to the share of the universe's total normative mass that thing makes up. Why would one endorse Lower Limits? Well, humans are feeling animals. We may be able to numb ourselves: we may be able to care about very little. But caring about nothing whatsoever? Perhaps this we just cannot do. Motivated in this way, Lower Limits is akin to Limits: it is a principle about human capability. Alternatively, we could construe Lower Limits as a normative principle. So construed, it says that it is impermissible to use less than a certain proportion of our emotional resources. Why would that be? Well perhaps it is wasteful for such richly endowed beings as us to be so unfeeling. And perhaps such wastefulness is not permissible. We will not explore these options further. This is because we have our doubts about the minimum permissible degrees of caring (see section 5.3). But, if those doubts are misplaced, this provides a promising route to a version of Proportionalism for permissible minimums. 
for Intrinsicism. Intrinsicism, remember, said that how much you are allowed to care about something is fixed by the thing's intrinsic properties. So consider any world that contains some fact, $f_{1}$, where $f_{1}$ is weighty enough that you are permitted to devote your entire emotional life to it. Now consider a second world in which two duplicates of $f_{1}$ exist, $f_{2}$ and $f_{3}$. Suppose, in this second world, you devote your entire emotional life to $f_{2}$. If Limits holds, this means you can devote none of your emotional life to $f_{3}$. So your attitudes would be out of proportion. But, if Congruity holds, this ensures you violate some of your obligations. Yet Intrinsicism says you are permitted to devote your entire emotional life to $f_{2}$. So it follows that you can permissibly do something that ensures you violate some of your obligations. And this is just to deny Necessary Means. So, Intrinsicism must deny either Limits, Congruity, or Necessary Means. In the next section, we will see how much mileage there is in such denials.

\section{OBJECTIONS TO THE MOTIVATION}

We now look at ways to reject the claims on which this deeper motivation rests. This is not just an exercise in rebutting objections (although it is that). It is an exercise in seeing how our view would change if one takes these objections seriously. We think that, even if you take these objections seriously, you are left with some version of Proportionalism. We first look at some objections to Congruity. Then, we look at an objection to each of Limits and Necessary Means.

\subsection{Too Demanding I}

Congruity may seem too demanding. It seems to imply that you should drain your life of personal concern. You should almost not care at all about your own joys and sorrows. You should care very little about the successes of your projects or the state of your health, or about the lives of your nearest and dearest. This is because (in our universe) a lot of other things matter. If you care proportionally about all these other things, you must care minimally about things of personal concern. But this may seem implausible. So, Congruity-the left-right of Congruity in particular-must be false.

We think this is an interesting objection to Congruity. But we do not think it refutes it. There seems to us two ways to reply to the objection. The first is to dig in one's heels: one could simply maintain that we should all care far less about our personal affairs than we normally do. This position has affinities with certain

importance. If the Egyptians lived glorious lives, then you ought to be happier about them than otherwise. This crowds out caring about other things. 
demanding, impersonal moral theories. Consider classical utilitarianism. This implies that we should do much less than we usually do to improve our personal affairs. We should act much more for others' benefit. The heel-digging position implies that we should care much less than we usually care about our personal affairs. We should care much more about other people. Both views go against much commonsense thinking. But neither, we think, is totally untenable. We might ordinarily do very poorly in both action and attitude. So, we think that if you find demanding, impersonal moral theories congenial, then you should find this position congenial.

The second response is more concessive. One might simply endorse an agent-relative theory of normative mass. Such a theory says that how weighty a thing is depends on whose perspective we assess it from. From your perspective, your wine collection might be a weighty matter. But from mine it is not so weighty. This view makes sense if you think that agent-relative properties contribute to normative mass. Such properties include those that reference you essentially. To assess how much of your joy and your suffering something has is to assess its agent-relative properties. Your projects usually involve more of your joy and your suffering than do those of anyone else. So, from your perspective, they may make up a larger proportion of the universe's normative mass than do those of anyone else. So, caring copiously about your personal affairs is compatible with Congruity. You just need an agent-relative theory of normative mass. With such a theory, Proportionalism should then be interpreted as itself agent-relative. It defines a different importance ranking for each person.

But maybe neither of these responses works. This would provide grounds to reject Congruity. But it need not be wholesale rejected. For it seems we can distinguish between different domains: the impersonal domain and the personal domain. We can understand this distinction as one between different kinds of facts. For a fact to be in your personal domain might just be for it to essentially concern your projects, or your loved ones, or your well-being. But facts in the impersonal domain do not essentially concern you at all. One way to think of the impersonal domain is as the domain of agent-neutral facts. The personal domain is then thought of as a subset of the domain of agent-relative facts. Once we make this distinction, we can say that Congruity applies only in the impersonal domain. It does not apply in the personal domain. On this view, Proportionalism may hold for one class of facts, but it need not hold for them all. We will discuss this view further in section 6.1.

\subsection{Too Demanding II}

Congruity may seem too demanding in a different way. It may allow us too lit- 
tle discretion in what we care about. For example, some of us choose to devote much of our emotional energy to economic injustice in England. But this injustice might involve less of what matters than does the malaria infection worldwide. After all, over two hundred million people suffer from malaria every year. Yet perhaps our attitudes are nonetheless fitting. Perhaps we have some choice over how much, relatively speaking, we care about worthy things. Yet that is inconsistent with Congruity. So, Congruity-the left-right of Congruity in particular-must be false.

One could respond to this by again digging in one's heels. Some people, such as classical utilitarians, think we have little choice over what we may do. Analogously, perhaps we have little choice over what we may care about. But suppose we take the objection more seriously. Even so, there is a reply to it. First, note that normative masses can be incommensurable. Perhaps there is no definite way that economic injustice and malaria weigh up. Rather, the normative mass of economic injustice is indeterminate, but determinately between a quarter and half of that of malaria. This calls for a minor modification of Congruity. Suppose one cares about economic injustice anywhere between a quarter and half as much as one cares about malaria. Then we should say one has fitting attitudes. ${ }^{18}$ This already gives us some choice over how much we care about things. But now let us exploit the agent-relative conception of normative mass we previously mentioned. On this conception it is plausible that the fact that you cared a lot about something in the past can make that thing weightier now. It can make it matter more for you today. So suppose, in June, you cared half as much about economic injustice as you did about malaria. This means economic injustice has a little extra normative mass in July. ${ }^{19}$ So, in July, perhaps you may care anywhere

More formally, we use a set of functions $N M=\left\{N M_{1}, N M_{2}, \ldots\right\}$ to jointly represent the normative mass of facts. We then say that your overall degrees of caring are fitting if and only if there is some function $N M_{i}$ in $N M$ that you satisfy Congruity with respect to. A version of our argument for Proportionalism then goes through.

Will malaria also have a little extra normative mass? Perhaps not. It might only get weightier when you have cared about it more than you had to, given your other attitudes. It might be voluntary devotion alone that adds mass to a thing. But we need not rely on that. The described mechanism works as long as you may treat economic injustice as gaining proportionately more mass than malaria. Suppose you may consistently treat malaria as getting 9 percent weightier but injustice as getting 11 percent weightier. Then, eventually, the normative mass of the injustice will exceed that of malaria. Why might this be permissible? Well, it is plausibly indeterminate how much mass your having cared about something adds to its existing mass. But your caring might determinately add between 9 and 11 percent to this existing mass. And perhaps you may consistently choose to care in line with the lower end of this range for malaria and the higher end for injustice. So you may consistently treat the injustice as getting proportionately weightier than malaria. 
between one and two-thirds as much about it as you do about malaria. Suppose you choose two-thirds. Then, in August, you may care anywhere between half and three-quarters as much about it as you do about malaria. We are off to the races. By iterating this process, you can step up how much you may care about worthy things. And you can do so without ever having unfitting attitudes. We think this gives us ample choice over our relative degrees of caring.

But maybe that is wrong. Maybe we need more choice. Yet it seems implausible that one has complete discretion over what one cares about. Suppose you care a lot about economic injustice. That does not mean that, when someone dies in front of you, you may remain completely cold. This would be to have unfitting attitudes. So we should not reject Congruity wholesale. We should reformulate it. We should say that one's attitudes are fitting when they are not too far out of proportion. There are a few ways to capture this. One way is to say that there is a factor $k>0$ such that, when $f$ is $n$ times the normative mass of $g$, your attitudes are fitting whenever you care between $k \times n$ and $k / n$ as much about $f$ as about $g$. So, for example, suppose that malaria has twice as much normative mass as economic injustice. If $k=4$, then it is permissible to care twice, but at most twice, as much about the injustice as about malaria. But there are other ways to capture the point. Whichever way we do it will get us a version of Proportionalism. ${ }^{20}$ If your attitudes cannot get too far out of proportion, then in weightier worlds you may care less about anything in particular.

\subsection{Too Permissive I}

Congruity may instead seem too permissive. This is because it allows you to care very little about certain things. It says that, if your attitudes are in proportion, then they are fitting. But your attitudes can be in proportion without you caring much about anything. So your attitudes can be fitting when you care about things very little. ${ }^{21}$ Yet suppose you are in the midst of a famine. And suppose you care very little about everything. Then this means you are allowed to also

20 The simple suggestion in the text gives us a somewhat complex version of Proportionalism. It implies that the importance of $f$ equals

$$
\frac{k \times N M(f)}{(k-1) \times N M(f)+N M(U)} .
$$

Indeed, your attitudes are proportionate in the sense of satisfying the right-hand side of Congruity when you care about nothing at all. To see this, imagine $f$ and $g$ are the only facts. Suppose you care to degree $\circ$ about $g$. But suppose $f$ is twice as weighty as $g$, so $N M(f)=$ $2 \times N M(g)$. Then you must care to degree $2 \times 0$ about $f$. But you do this by caring to degree 0 about $f$. So, when you do not care about anything, your attitudes satisfy the right-hand side of Congruity. 
care proportionally little about those starving around you. Yet one might object that caring so little about such a famine is pathologically cold. You are obligated to care some minimum amount about someone starving in front of you. So, Congruity - the right-left of Congruity in particular-must be false.

We think this is an interesting objection. But here is a reply to it. This objection, we think, has two sources. First, most of us care a lot about some things. We care a lot about our jobs, our partners, our receding hairlines, and so on. So, for most of us, when we care little about someone starving, our attitudes are out of proportion. So, they are impermissible. But, when this is the source of the objection, it poses little threat to Congruity. Congruity is consistent with this claim. The second source, we think, concerns the link between moral normativity and fitting attitudes. We suggested one such link in section 1. We suggested that one had moral reason to care fittingly about things that matter morally. But perhaps there are other links. In particular, perhaps one does something morally wrong when one cares very little about what matters morally. One's attitudes might not be unfitting, in this case, but they might nonetheless be morally suspect. Yet when this is the source of the objection, it again poses little threat to Congruity. Congruity is a principle about the type of normativity confined to caring, not moral normativity. So, we do not think this objection refutes Congruity after all.

But perhaps that is wrong. Perhaps there are some facts about which you must care to some minimum degree. Nonetheless, this does not really imperil Proportionalism. This is because Proportionalism is a thesis about the maximum degrees you can care about things. It identifies some amount as the maximum you can permissibly care about something. We only used the right-left of Congruity to establish that caring about something this much is permissible. But the objection does not dispute this. It does not suggest that caring up to this maximum amount is impermissible. It says caring below a minimum amount is impermissible. So let us just assume that you are allowed to care up to this amount. But assume you must still keep your attitudes in proportion. Then Proportionalism follows anyway. So, if we maintain this objection, it is not that we must reject Proportionalism. It is just that Proportionalism is not the whole story. When saying how much you can care about things, we must tell a story about minimums as well as maximums. But Proportionalism may be an essential part of the story without being the whole story. ${ }^{22}$ objection is maintained, we may not need a non-proportionalist story. 


\subsection{Too Permissive II}

Congruity may seem too permissive in a different way. If you live in a universe where nothing much matters, then Congruity permits you to care a lot about trifles. For instance, suppose you lived in a world with just you and the James Bond films. According to Congruity, you are then permitted to care enormously about Bond. But one might object that caring so much about Bond is utterly over the top. Even in such a world, there is an upper limit to how much you can care about 007. On this view, you just are not allowed to care that much about certain things. So, Congruity - the right-left of Congruity in particular-must be false.

This objection would imperil Proportionalism. For suppose there are upper limits independent of Proportionalism. Then the degree of caring identified by Proportionalism might exceed the maximum permissible degree. But we are skeptical of the objection. We think its force comes from the fact that, in our world, the Bond films are rather trivial. This is because our world is full of important things. So, in our world, one should not care too much about Bond. Yet suppose you really are in a universe where nothing but Bond matters. Then we see no reason why you cannot devote large parts of your emotional life to Bond. Why must you twiddle your emotional thumbs? Why must you let part of your emotional life go to waste? It seems puritanical to deny us access to the full expression of our emotional capacity. So, we doubt there are independent constraints on caring of this sort.

But maybe that is wrong. Maybe there are some things you just are not allowed to care that much about. Nonetheless, we think that there must be a large class of facts that are free of such constraints. Consider, for example, the Sichuan earthquake. This was a tragedy. Over eighty thousand people died. We think that, apart from Congruity itself, there are no constraints on how much you can care about such a thing. If it were the only thing that ever happened, you would not be mistaken in devoting all your emotional resources to it. We also doubt that, apart from Congruity, there are any constraints on how much you can care about the death of a loved one. And, to boot, we think you can care as much as you want about Sunset Boulevard. So the above argument will go through with respect to this class of facts. In other words, Proportionalism holds for one class of facts, but not them all.

\subsection{Not Limiting Enough}

We have just discussed some objections to Congruity. We now discuss an objection to Limits. Limits says that there is a maximum amount you are able to care about things, but you are able to have any attitudes consistent with this 
maximum. This objection says that Limits is too permissive. It says that there are some collections of attitudes one cannot have, despite their consistency with the limit. Suppose, for instance, that you just cannot bring yourself to care about bird-watching. Maybe your co-author likes bird-watching very much. But it is just not for you. Swifts and swallows (and even sparrows) leave you cold. Bird-watching is something you cannot care much about, and this incapacity has nothing to do with you having exhausted your overall emotional resources.

This is another interesting objection. But we do not think it refutes Limits. Rather, it shows that Limits invokes a specific type of modality, and a specific notion of importance. The type of modality just described seems like psychological possibility. It is psychologically possible for you to have some attitudes if it is metaphysically possible and consistent with central facts about your psychology. But psychological modality is very variable: what is psychologically possible for someone depends on their peculiar quirks and foibles. So we doubt that the notion of importance explicated in these terms is that interesting. It is too contingent, and so lacks generality. Limits characterizes a different type of modality, which we might call Limits-possibility: it is Limits-possible for you to have some attitudes if it is metaphysically possible and consistent with Limits. ${ }^{23}$ We think that this gives rise to an interesting notion of importance. This notion is sensitive to the fact that we are finite, but insensitive to any of our further idiosyncrasies.

But perhaps this is wrong. Perhaps the only interesting notion of importance is the one keyed to psychological possibility. Nonetheless, Congruity and Necessary Means still get us a kind of proportional thinking for this notion. To see this, consider the fact $f_{1}$ that you are least able to care about, in proportion to its share of the universe's total normative mass. Maybe this is a very weighty fact, but one you can only bring yourself to care about moderately. Or maybe it is a lightweight fact, but one you can hardly bring yourself to care about at all. Congruity and Necessary Means then entail that we must adjust how much you can permissibly care about any other fact, $f_{k}$, by how much you can care about this fact. To see how, first identify the fraction of your emotional life you are able devote to $f_{1}$. Then see what fraction of the universe's total normative mass $f_{1}$ makes up. Then divide the former by the latter. This new fraction identifies how much you can care about $f_{1}$ in proportion to how much you are permitted to care about it. How much of your emotional life you are allowed to devote to any $f_{k}$ is then this fraction multiplied by the fraction of the universe's total normative mass

23 Limits-Possibility might just be physical possibility. We doubt anyone is physically incapable of caring about bird-watching. This means we need not think of it as a novel, unfamiliar kind of possibility. 
that $f_{k}$ makes up. So, even if this objection carries the day, you are stuck with a type of proportional thinking.

\subsection{Necessary Means Equivocates}

Finally, we will discuss an objection to Necessary Means. Necessary Means says that you are not permitted to have attitudes that ensure you violate an obligation. The objection says that Necessary Means rests on an equivocation. It is a plausible principle for moral permissibility and practical permissibility. But the notion of permissibility we are using is that which rules attitudes of caring. And there might be no reason to think Necessary Means holds for this notion. Having some attitude might ensure you violate some obligation, without that attitude being impermissible qua attitude. So the argument for Proportionalism fails at the final step.

This objection is also interesting. But we doubt it goes through. We think that the plausibility of Necessary Means in these other cases is probative. The normativity that rules attitudes of caring seems enough like these other types of normativity that we expect it to obey similar structural rules. That Necessary Means holds in these cases is evidence that it holds for the type of normativity that governs attitudes of caring. So, we think Necessary Means does hold for the type of normativity with which we are concerned.

But perhaps this is wrong. Then Proportionalism does not follow for the normativity specific to attitudes of caring. Nonetheless, we can identify a kind of normativity for which it does follow. It follows for practical rationality, holding fixed certain desires. For suppose we hold fixed our desire to have overall fitting attitudes. The argument in section 4 shows that conforming to Proportionalism must be a necessary means to having overall fitting attitudes. And practical rationality does obey a necessary means principle. If you want $p$, and $q$ is a necessary means to $p$, then you ought (practically speaking) to see to it that $q$. So it follows that you ought, practically speaking, to conform to Proportionalism. ${ }^{24}$ So Proportionalism follows for the practical ought, holding fixed our desire to have fitting attitudes. This version of Proportionalism has a somewhat pragmatic air. It identifies what, practically speaking, we need to do if we want fitting attitudes. But we think most of us do want fitting attitudes. And we think this desire makes sense: having fitting attitudes is part of a life well lived. If you actually only care

24 This necessary-means principle may be wide-scope (see, e.g., Broome, "Wide or Narrow Scope?"). So Proportionalism follows for sure only with Necessary Detachment. Necessary Detachment says that if $p$ is fixed and you ought to see to it that $(p \rightarrow q)$, then you ought to see to it that $q$. 
about Bond, then your life is impaired. So, even if you deny Necessary Means, in a practical sense you remain bound by Proportionalism.

\section{EXTENDING PROPORTIONAL THINKING}

That completes our account of importance. We know of no fatal objections to this account, it fits some intuitive data, and it has a nice motivation. So we think the account is not obviously false. It may even be true. We also just identified several fallback positions that count as kinds of Proportionalism. So, if it is not true in letter, it might still be true in spirit. In the rest of the paper, we will explore ways to extend these views. We first look at how one might extend the fallback position identified in section 5.1. We then look at extensions one could make to any of these views, including full-blooded Proportionalism. We think one can take or leave these extensions. But this exploration helps show the implications (and fruitfulness!) of proportional thinking.

\subsection{Domain-Specific Proportional Thinking}

In section 5.1, we suggested that Proportionalism might only apply in the impersonal domain. But we did not say how you should deal out your degrees of caring in other domains. Nor did we say how you should deal out your degrees of caring between domains. We think proportional thinking can be extended to both issues. In this section, we will show how this might be done. This means, we think, that such thinking is a much wider phenomenon than that captured by Proportionalism alone. You can adopt it even if you restrict or reject this view.

Let us begin with the personal domain. We previously suggested that each person's personal domain is made up of the facts that referenced them essentially. But we did not say how much you are allowed to care about each fact. So, consider something in your personal domain. Consider, for instance, that fiery love affair you had in college. What is the most you can permissibly care about this? That may depend on what the rest of your life looks like. If the rest of your life is full of only Muzak and potatoes, then this affair is very important indeed. You can devote a lot of your emotional life to it. But if you have lived a more full life, perhaps a life full of such affairs, then the college dalliance is less important. You can devote less of your emotional life to it. So, the importance of any particular fact in your personal domain diminishes as your personal domain gets weightier. The more full your life, the less personally important is any individual event in your life.

Here is how to spell this out. Let $I_{p}(f)$ be how much concern you can permis- 
sibly devote to some fact, $f$, in your personal domain. Let $N M(P)$ be the normative mass of the entirety of your personal domain. Then this view says:

$$
I_{p}(f)=\frac{N M(f)}{N M(P)} .
$$

This view is formally similar to Proportionalism. In both cases, the importance of a fact is its normative mass adjusted for how much normative mass there is in some wider thing. With Proportionalism the wider thing is the universe. With this view the wider thing is the entirety of your personal domain. So this is an extension of proportional thinking to the personal domain.

Let us now see how proportional thinking can also extend to the domain of rights. This domain is made up of essentially rights-involving facts. So imagine you punch someone. If this is the only rights violation that ever happened, then it looks quite important. Feelings of penitence may swell your breast. But you might instead live in a more callous world. You might live in a world in which rights violations are commonplace. Then perhaps this violation is less important. It would be self-indulgent to wail and moan over this rights violation, when rights are being violated all around. We can represent this as before. Let $I_{r}(f)$ be how much concern you can permissibly devote to some fact, $f$, in the domain of rights. Let $N M(R)$ be the normative mass of the entirety of the domain of rights. Then this view says:

$$
I_{r}(f)=\frac{N M(f)}{N M(R)} .
$$

This gives us two examples of domains - apart from the impersonal—in which proportional thinking may apply. We see these examples as proofs of concept. We are unsure how exactly one should demarcate the domains if engaging in domain-specific proportional thinking. Perhaps the domain of virtue should have its place alongside these other domains. Perhaps we should include the domain of departmental politics. We do not know. The important point is just that, even if Proportionalism itself is too general, proportional thinking may not be.

So, how should you dole out your degrees of caring between domains? We will note two views on this. We start with a non-proportionalist view. On this view, you can devote a fixed proportion of your emotional life to each domain. The simplest way to implement this is to say you can devote the same amount to each domain, and together these sum to the entirety of your emotional life. So, you can devote a third of your emotional life to the impersonal domain, a third to the personal domain, and a third to the domain of rights. On this view, how much you can care about the things in some domain never changes. And, on 
this particular implementation, you cannot trade-off between domains. You can never devote more than a third of your emotional life to the impersonal domain, even if you do not care at all about the other domains.

But we prefer a second, more proportionalist view. On this second view, how much you can care about each domain can change. It is proportional to-but not the same as - the fraction of the universe's total normative mass that a domain makes up. For instance, suppose that the normative mass of the personal domain is a quarter that of the entire universe. You might nonetheless be allowed to devote half your emotional life to it. But suppose it is an eighth of the mass of the entire universe. Then you might be allowed to devote a quarter of your emotional life to it. In other words, there is some factor, $j$, such that the proportion of your emotional life you can devote to things in your personal domain is $j \times N M(P) / N M(U)$. If this factor is large enough, you can care a lot about your personal affairs. But the weightier the universe, the less you can care about such matters. We think this view captures much of the virtue of Proportionalism, without its possibly overbearing character. So, we think it is the best way to implement domain-specific proportional thinking. ${ }^{25}$

\subsection{Reasons}

We have so far focused on the permissibility of attitudes. In this section, we look at how to extend proportional thinking to the strength of certain reasons. The simplest way to do this is to assume that there are links between fitting attitudes and reasons. In particular, it seems that we can think of certain emotions-hope, pleasure, anticipation — as positive. We can think of others-terror, displeasure, trepidation-as negative. Some of these positive emotions may connect to reasons to bring about something. Some of the negative emotions may connect to reasons to prevent that thing. We will call these reasons consequentialist reasons. So this claim comes down to:

Bridge: How much consequentialist reason one could have to bring about $f$ is proportional to how much of these positive emotions one can (permissibly) direct toward $f$. How much consequentialist reason one could have to prevent $f$ is proportional to how much of these negative emotions one can (permissibly) direct toward $f$.

Suppose a principle like this is true. Then a simple extension of Proportional-

25 Every such view is extensionally equivalent to one of the agent-relative versions of Proportionalism mentioned in section 5.1. But they differ in their conceptions of normative mass. Domain-specific views have no need of an agent-relative conception of normative mass. But this is essential to agent-relative versions of Proportionalism. 
ism will extend proportional thinking to reasons. This extension holds that how much of these positive or negative emotions one can feel about any fact is proportional to the normative mass of the entire universe. So, how much consequentialist reason one has to bring about (or prevent) some fact is proportional to that fact's share of the universe's entire normative mass. The weightier the universe, the less weighty are consequentialist reasons.

In the rest of this section, we will look at two issues this extension generates. The first issue is straightforward. Even if the strength of consequentialist reasons varies with the weight of the entire universe, the strength of other kinds of reasons may not. Call a reason that does not vary in this way a local reason. It follows that, the weightier the world, the stronger are local reasons relative to nonlocal reasons. Here is a concrete example. Suppose that reasons not to violate rights are such local reasons. The strength of one's reason not to punch people is not diminished by how much joy and sorrow is in Alpha Centauri. This implies that, in weightier worlds, reasons not to violate rights become relatively strong. This is because, in weightier worlds, the strength of consequentialist reasons is diminished. This is an interesting implication. It suggests that the weightier the world is, the fewer are the circumstances in which a rights violation is permissible. In lightweight worlds, consequentialist considerations win out. But, in heavyweight worlds, rights rule the day.

The second issue will take longer to lay out. This is a choice point. If we extend Proportionalism to reasons, we face the following question: What should we do under conditions of uncertainty? The standard view is that one should do whatever has the highest expected value. An action's expected value is the value it would realize in each state of the world, weighted by how likely that state is. The Proportionalist can adopt this view. They can say that, when we do not know what the effects of our actions are, we should do the thing with the highest expected value. The Proportionalist flavor comes in when assessing the importance of such prospects. Their importance, one can say, is their expected value divided by the normative mass of the whole universe. It is not their expected value alone.

But there is a second, more radical option. This involves a different view of how one should act under conditions of uncertainty. This different view says that one should do what one has the highest expected strength of reason to do. The expected strength of a reason is how strong that reason would be in each state of the world, weighted by how likely that state is. To put this formally, let $R_{i}(A)$ be the strength of reason one has to perform $A$ in the $i$ th state of the world. Then the expected strength of one's reason to $A$ is: 


$$
\operatorname{ESR}(A)=\sum_{i} R_{i}(A) \times \operatorname{PR}\left(S_{i}\right) .
$$

This view seems defensible to us. Indeed, expected value maximization may seem right only because, in many cases, it matches expected strength of reason maximization. So, suppose you think that we should do what maximizes expected strength of reason. We then get a radical consequence. There will be cases where you should not maximize expected value. For suppose Proportionalism is extended to reasons. Then maximizing expected strength of reasons will often mean maximizing expected proportional improvements. But expected proportional improvement and expected value do not coincide. They diverge in cases where you can have big proportional changes that are, in absolute terms, relatively small. So, in such cases, you should not maximize expected value. What do such cases look like? Here is an example:

Super-technology: Suppose you can develop the super-technology. If humanity is alone in the universe, then this will make the universe much better. It will allow us to bring life to worlds otherwise empty of value. But suppose the universe is teeming with intelligent life. Then the universe is already overflowing with value. This might seem like reason to rejoice. But, alas, man cannot control his warlike nature. We would inevitably use the super-technology to bring terror to other worlds. This will make the universe much worse. Should you develop the super-technology?

Let us formalize the case. For simplicity, suppose the world where we are alone has a normative mass of 4 . Suppose the one where we have company has a normative mass of 40 . These assumptions track the fact that more of what matters has happened in the latter than the former. Now let $n \rightarrow k$ represent a move from a world of value $n$ to one of value $k$. Then we can write this decision problem as:

\begin{tabular}{l|c|c} 
States of the World & $N M(U)=4$ & $N M(U)=40$ \\
Probabilities & 0.5 & 0.5 \\
\hline Develop & $1 \rightarrow 2$ & $10 \rightarrow 8$ \\
Do Not Develop & $1 \rightarrow 1$ & $10 \rightarrow 10$
\end{tabular}

So formalized, it is clear that the expected value of not developing the super-technology exceeds that of developing it. But the expected strength of reasons to develop it exceeds that of not developing it. The relevant calculations are:

$$
\begin{gathered}
E S R(\text { Develop })=(0.5 \times 1 / 4)+(0.5 \times-2 / 40)=0.1, \\
\operatorname{ESR}(\text { Do Not Develop })=(0.5 \times \%)+(0.5 \times \%)=0 .
\end{gathered}
$$


So, if you should maximize expected strength of reasons, you should develop the super-technology. So, you should not do what maximizes expected value. This is why we call this a radical option. It materially diverges from the standard view. We are unsure whether the radical or conservative option is better. But we think this is an important choice point generated by applying Proportionalism to reasons. More generally, we think extending Proportionalism to reasons raises interesting, and sui generis, issues.

\subsection{Subjective Proportionalism}

Let us look at one final extension of Proportionalism. This also has to do with expectations. Namely, people often distinguish between objective and subjective reasons. ${ }^{26}$ Suppose you have a glass of clear liquid in front of you. You are thirsty. You think the clear liquid is water. So you have good subjective reason to drink from the glass. But, actually, what is in the glass is poison. So you have got an objective reason not to drink it. Roughly, the distinction is this: objective reasons depend on just the facts. But subjective reasons depend on what you think the facts are, or perhaps what you ought to think the facts are.

This distinction can also be made among fitting attitudes. Proportionalism has an objective character. How much normative mass you think the universe has does not matter. All that matters is how much normative mass it does have. But there seems to be room for a subjective notion of importance. This would let what you think, or perhaps should think, about normative masses determine how much you can permissibly care about something.

It is straightforward to characterize such a notion. We first help ourselves to the notion of expected normative mass. Something's expected normative mass is the probability-weighted average of the normative masses it might have. For a fact, $f$, we denote this $\operatorname{ENM}(f)$. We then say that the subjective importance of a fact just is its expected normative mass divided by the expected normative mass of the entire universe. In other words:

$$
I_{s}(f)=\frac{E N M(f)}{\operatorname{ENM}(U)} .
$$

We can read the relevant probabilities either as actual credences or as evidential probabilities. On the first reading, this gives you a notion of importance dependent on what you actually think. On the second, it gives you a notion of importance dependent on what you ought (epistemically speaking) to think. Subjective importance and subjective reasons seem interesting on the same grounds.

26 There is a vast literature on this distinction. For an extensive discussion, see, e.g., Zimmermann, Living with Uncertainty. 
They both satisfy intuitions that our beliefs (or our evidence) should matter to our obligations. And they are perhaps, in a sense, more action-guiding. We could be deeply uncertain what the universe's total normative mass is, but we might still be able to work up an expectation. So we can still establish how much, subjectively speaking, we can permissibly care about something. This notion of subjective importance may be a worthwhile extension to Proportionalism. It is the last extension to Proportionalism we will look at.

\section{CONCLUSION}

We have presented a theory of importance. This theory says that how important something is is determined by the proportional contribution it makes to the total normative mass of the whole universe. We think this fits some intuitive data, has a nice motivation, and can be extended in various interesting ways. But enough of that. Suppose Proportionalism is true. How should you feel about this? Well, it depends. If you are rejoicing at the splendor of your life, proud of your achievements, and excited about your projects, then our view will come as a setback. You must keep it in perspective: in all likelihood, the good in your life is less important than you think. You need to tone down your jubilance. On the other hand, if you are overwhelmed by woe, shattered by loss, trembling with concern, then our view may come as a comfort. You may keep it in perspective: in all likelihood, the evil in your life is less important than you think. You need not be so devastated. You may, we think, cease taking yourself so seriously. ${ }^{27}$

New York University adam.lovett@nyu.edu

University of Zurich stefan.riedener@philos.uzh.ch

\section{REFERENCES}

Bartels, Daniel. "Proportion Dominance: The Generality and Variability of Fa-

27 For helpful comments on earlier drafts of this paper, we would like to thank Alex Dietz, Arden Koehler, Robert Long, Andreas Mogensen, Lukas Naegeli, Jacob Nebel, Philipp Reichling, Peter Schaber, Samuel Scheffler, Daniel Sharp, and Jake Zuehl. We also thank the Global Priorities Institute in Oxford for hosting us while we were working on this paper. 
voring Relative Savings over Absolute Savings." Organizational Behavior and Human Decision Processes 100, no. 1 (May 2006): 76-95.

Bostrom, Nick. "Infinite Ethics." Analysis and Metaphysics 10 (2011): 9-59.

Broome, John. "Wide or Narrow Scope?” Mind 116, no. 462 (April 2007): 359-70. Bykvist, Krister. "No Good Fit: Why the Fitting Attitude Analysis of Value Fails." Mind 118, no. 469 (January 2009): 1-30.

D’Arms, Justin, and Daniel Jacobson. "The Moralistic Fallacy: On the 'Appropriateness' of Emotions." Philosophy and Phenomenological Research 61, no. 1 (July 2000): 65-90.

Fetherstonhaugh, David, Paul Slovic, Stephen M. Johnson, and James Friedrich. "Insensitivity to the Value of Human Life: A Study of Psychophysical Numbing." Journal of Risk and Uncertainty 14, no. 3 (May/June 1997): 283-300.

Firth, Roderick. "Ethical Absolutism and the Ideal Observer." Philosophy and Phenomenological Research 12, no. 3 (March 1952): 317-45.

Glover, Jonathan, and M.J. Scott-Taggart. "It Makes No Difference Whether or Not I Do It.” Aristotelian Society Supplementary Volume 49 (1975): 171-209.

Loewenstein, George, and Karen E. Jenni. "Explaining the 'Identifiable Victim Effect." Journal of Risk and Uncertainty 14, no. 3 (1997): 235-57.

MacAskill, William. Doing Good Better: How Effective Altruism Can Help You Make a Difference. New York: Penguin, 2015.

McMahan, Jeff. "Problems of Population Theory." Ethics 92, no. 1 (October 1981): 96-127.

Nagel, Thomas. “The Absurd.” Journal of Philosophy 68, no. 20 (October 1971): 716-27.

Parfit, Derek. Reasons and Persons. Oxford: Oxford University Press, 1984.

Rabinowicz, Wlodek, and Toni Rønnow-Rasmussen. "The Strike of the Demon:

On Fitting Pro-Attitudes and Value." Ethics 114, no. 3 (April 2004): 391-423.

Railton, Peter. "Moral Realism." Philosophical Review 95, no. 2 (April 1986): 163207.

Singer, Peter. The Life You Can Save: Acting Now to Stop World Poverty. New York: Random House, 2009.

Smith, Michael. The Moral Problem. Oxford: Blackwell, 1994.

Unger, Peter. Living High and Letting Die: Our Illusion of Innocence. New York: Oxford University Press, 1996.

Zimmermann, Michael. Living with Uncertainty: The Moral Significance of Ignorance. Cambridge: Cambridge University Press, 2008. 